\title{
Extreme homozygosity in Southern Hemisphere populations of Deladenus siricidicola, a biological control agent of Sirex noctilio
}

\author{
X. Osmond Mlonyeni ${ }^{a}$, Brenda D. Wingfield ${ }^{a}$, Michael J. Wingfield ${ }^{a}$, Rodrigo Ahumada ${ }^{b}$, Paula Klasmer ${ }^{c}$, \\ Isabel Leal ${ }^{\mathrm{d}}$, Peter de Groot ${ }^{\mathrm{e}}$, Bernard Slippers ${ }^{\mathrm{a}, *}$ \\ a Department of Genetics, Forestry and Agricultural Biotechnology Institute, University of Pretoria, Pretoria 0002, South Africa \\ ${ }^{\mathrm{b}}$ Bioforest S.A., 70-C, Concepción, Chile \\ 'Campo Forestal General San Martin, Estación Experimental Bariloche Instituto Nacional de Tecnología, Agropecuaria, El Bolsón, Rio Negro, Argentina \\ ${ }^{\mathrm{d}}$ Canadian Forest Service, Pacific Forestry Centre, Natural Resources Canada, Victoria, British Columbia, Canada V8Z 1 M5

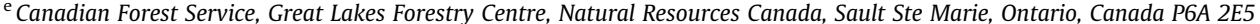

\section{H I G H L I G H T S}

- High throughput development of microsatellite markers for Deladenus siricidicola populations.

D. siricidicola populations in the Southern Hemisphere lacks any diversity.

- The diversity reflects the breeding and distribution history of the nematode.

- Southern Hemisphere and Canadian populations are distinct.

- Management using the nematode should be adapted using the data provided here.

\section{A R T I C L E I N F O}

\section{Article history:}

Received 1 February 2011

Accepted 9 September 2011

Available online 16 September 2011

\section{Keywords:}

Deladenus (=Beddingia) siricidicola

Sirex woodwasp

Entomopathogenic nematode

Microsatellites

Nematode population genetics

\section{G R A P H I C A L A B S T R A C T}

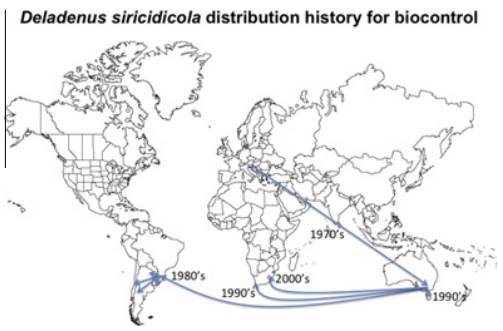

\begin{abstract}
A B S T R A C T
The woodwasp Sirex noctilio, together with its mutualistic fungal symbiont Amylostereum areolatum, is the most damaging invasive pest of Pinus spp. in the Southern Hemisphere. The nematode Deladenus siricidicola parasitizes Sirex noctilio larvae and is the most effective biological control agent against this woodwasp. Nothing is known regarding the genetic diversity of $D$. siricidicola, even though such knowledge would be invaluable in improving sustainable biological control programs. The aim of this study was to develop microsatellite markers to study the genetic diversity of $D$. siricidicola populations. Microsatellite enrichment was performed using Fast Isolation by AFLP of Sequences Containing repeats (FIASCO) and fragments were then sequenced using 454 GS-FLX pyrosequencing. From the 1.2 megabases of sequence data, 166 microsatellite containing contigs were identified. Twenty-six primer pairs were designed using the web-based program Primer3 and screened for polymorphism in populations of the nematode from different sources in the Southern Hemisphere. Seventeen primers amplified microsatellite-containing loci of interest. No length polymorphism was present in any of the microsatellite repeats in these populations. Regions flanking the microsatellites also showed no polymorphism, except for one transition observed in an Argentinean strain for locus Ds316. Twelve of the loci showed polymorphism between the Southern Hemisphere and Canadian sources of $D$. siricidicola. The lack of diversity in Southern Hemisphere populations of $D$. siricidicola could affect the ability of this nematode to adapt to different environments and host types where it is used in biological control programs, and should thus be considered as a factor in future control strategies and research projects.
\end{abstract}

(ㄷ) 2011 Elsevier Inc. All rights reserved.

\footnotetext{
* Corresponding author. Fax: +27 124203960.

E-mail address: Bernard.slippers@fabi.up.ac.za (B. Slippers).
} 


\section{Introduction}

The nematode Deladenus siricidicola Bedding is the primary and most effective biological control agent against the invasive woodwasp Sirex noctilioF. This wasp and its obligate fungal mutualist, Amylostereum areolatum Boidin, is one of the most serious pests of Pinus spp. in forestry plantations in the Southern Hemisphere. Deladenus siricidicola has a bi-cyclic life cycle (Bedding, 1967; Bedding, 1972; Bedding and Akhurst, 1978). During the free-living cycle, the nematode feeds on the basidiomycete fungus $A$. areolatum growing in the infested trees. In its parasitic cycle, the nematode penetrates and develops inside the wasp larvae. Eggs of the nematode are triggered to convert to the infective form by the high $\mathrm{CO}_{2}$ and low $\mathrm{pH}$ conditions that surround the Sirex larvae (Bedding, 1967; 1972; Bedding and Iede, 2005). Once wasp pupation begins, the fertilized female nematodes release juveniles that migrate and infest the reproductive organs, eventually entering the eggs and sterilizing the female Sirex noctilio.

Sirex noctilio is native to Eurasia and North Africa (Morgan, 1968; Spradbery and Kirk, 1978) and was accidentally introduced into the Southern Hemisphere via New Zealand in the early 1900 's. Subsequent biological invasions were observed in Australia in 1952 (Neumann et al., 1987), Uruguay in 1980 (Maderni, 1998), Argentina in 1985 (Klasmer et al., 1998), Brazil in 1988 (Iede et al., 1998), South Africa in 1994 (Tribe, 1995), Chile in 2001 (Ahumada, 2002) and more recently the United States of America in 2005 (Hoebeke et al., 2005) and Canada (de Groot et al., 2006).

Deladenus siricidicola was discovered in 1962 in New Zealand, parasitizing S. noctilio (Zondag, 1969). An extensive research program was established in New Zealand and Australia to characterize the biology of the nematode, and to develop a biological control program. This program eventually resulted in the selection of a virulent Hungarian strain (Sopron strain) of $D$. siricidicola for use as a biocontrol agent (Bedding and Akhurst, 1974; Zondag, 1979). This strain was widely released in Sirex-infested plantations in Australia. In the late 1980's the Sopron strain was reported to have lost its virulence, presumably due to continuous mass rearing on the fungal symbiont (Haugen and Underdown, 1990; Bedding and Iede, 2005). A virulent strain of the nematode was then isolated from the Kamona forest (site of the original release of virulent Sopron strains) in Tasmania, and this Kamona strain was used to inoculate infested plantations in Australia (Bedding and Iede, 2005). The success of the program led to the distribution of the Kamona strain to other Sirex-infested countries in the Southern Hemisphere. A strain known as 'Encrusilada do sul' was isolated from the field-infested pines in Brazil and selected for biological control due to its higher level of virulence. The relationship between the Brazilian strain and Kamona has not been determined.

The rate of $D$. siricidicola parasitism of Sirex wasps in inoculated trees varies between $5->90 \%$ in different regions of the Southern Hemisphere (Hurley et al., 2007). These authors hypothesized that a number of factors could affect this variation in parasitism by the nematode, including inoculation techniques, moisture content of the wood, loss of virulence of the nematode, incompatibility among the specific populations of $S$. noctilio, A. areolatum and $D$. siricidicola in that area, competition of saprophytic fungi with A. areolatum, and pine species affected. In a subsequent study, Hurley et al. (2008) excluded inoculation techniques and loss of nematode virulence as factors affecting $D$. siricidicola parasitism in South Africa. While wood moisture content affected parasitism levels, this did not explain the breadth of the observed variation. This highlights the possible role of other factors that might affect nematode efficacy and that remain to be tested.

Population diversity studies on $D$. siricidicola and $S$. noctilio have yet to be conducted. The aim of this study was to characterize microsatellite containing markers specific for $D$. siricidicola that could be used in studies of population genetic variation. These markers are then applied to assess the diversity among strains from populations of $D$. siricidicola from Australia, Argentina, Brazil and South Africa as well as to determine the level of diversity and the historical relationship between these nematode strains. This diversity is also compared with that of strains of the nematode that have recently been discovered in Canada (Yu et al., 2009).

\section{Materials and methods}

\section{Nematode sources and harvesting}

Sources of $D$. siricidicola were from Argentina (two sources; Argentina1, Argentina2), Australia, Brazil and South Africa for the Southern Hemisphere, and Canada from the Northern Hemisphere (four sources; 181, 184, 484 and 1089). Nematode sources refer to cultures of the nematode made from an individual wasp in the different regions of origin. All nematode cultures are maintained by the Tree Protection Co-operative Program based in the Forestry and Agricultural Biotechnology Institute (FABI), University of Pretoria, South Africa (http://www.fabinet.up.ac.za).

Nematodes were harvested from cultures grown in $500 \mathrm{ml}$ Erlenmeyer flasks containing wheat, rice and A. areolatum, or on potato dextrose agar (PDA) plates onto which $A$. areolatum had been inoculated (Bedding and Akhurst, 1974). Nematodes were harvested from the flasks by soaking ( $15 \mathrm{~min}$.) and washing with distilled $\mathrm{H}_{2} \mathrm{O}$. The nematode suspension was poured through a sieve into $1 \mathrm{~L}$ beakers and nematodes were allowed to settle for $20 \mathrm{~min}$. For isolation from Petri dish culture plates, sterile distilled water (SABAX water, Adcock Ingram Ltd., Bryanston, RSA) was added to the plates to cover the cultures and left to stand for $20 \mathrm{~min}$, while swirling four times during this period. The suspension was decanted into $50 \mathrm{ml}$ beakers and nematodes were allowed to settle for $10 \mathrm{~min}$. After settling, for both of the above techniques, excess water was discarded and nematodes were washed four times at intervals of $20 \mathrm{~min}$ in sterile distilled water, each time discarding excess water, prior to the subsequent wash. Following the last wash, $1 \mathrm{ml}$ of sample was transferred to $1.5 \mathrm{ml}$ Eppendorf tubes, centrifuged at $13000 \mathrm{rpm}$ for $3 \mathrm{~min}$, the supernatant was discarded and the sediment was used for DNA extraction.

\section{DNA extraction}

A phenol-chloroform DNA extraction method was used to extract DNA for microsatellite enrichment and discovery, from large numbers of harvested nematodes from flasks as described above (source Argentina1). The nucleic acids were precipitated by 0.1 volume of $2 \mathrm{M} \mathrm{NaAc}$ ( $\mathrm{pH} 5.6$ ) and $1 \mathrm{ml}$ of $100 \% \mathrm{EtOH}$. The sample was left overnight and the DNA was obtained after centrifugation (Eppendorf Centrifuge 5417C), washing the pellet with $1 \mathrm{ml}$ of $70 \% \mathrm{EtOH}$, vacuum drying at $45^{\circ} \mathrm{C}$ for $5 \mathrm{~min}$ (Concentrator 5301 ), and resuspending with $100 \mu \mathrm{l}$ of Sabax water. Five microlitres of RNase were added to the resuspended sample, followed by incubation on HB-2 heat blocks (Wealtec Corporation) at $37^{\circ} \mathrm{C}$ for $3 \mathrm{~h}$.

Pooled DNA extractions from all nematode sources were performed using PrepMan ${ }^{\mathrm{TM}}$ (Applied Biosystems, California, USA) in $20 \mu \mathrm{l}$, and using nematodes harvested from PDA culture plates as described above. Fifteen microlitres of PrepMan Ultra sample Preparation Reagent and a $2 \mathrm{~mm}$-diameter sterile metal ball was added to each sample-containing Eppendorf tube. The samples were shaken at a frequency of 30 vibrations/s for 3 min using the Retsch ${ }^{\circledR}$ MM 301 (Retsch, Germany). The metal balls were then removed with a magnetic stick, and the samples vortexed for $15 \mathrm{~s}$ and incubated at $100{ }^{\circ} \mathrm{C}$ for $10 \mathrm{~min}$. Following incubation, samples were centrifuged at $13000 \mathrm{rpm}$ for $3 \mathrm{~min}$, after which the DNA 
containing supernatant was transferred into sterile $1.5 \mathrm{ml}$ Eppendorf tubes. The concentration of the resulting DNA was determined using the ND-1000 UV/Vis Spectrometer (NanoDrop Technologies, Wilmington, DE 19810 USA).

\section{Microsatellite enrichment and pyrosequencing}

The fast isolation by AFLP sequence containing repeats (FIASCO) method (Zane et al., 2002) with modifications (M-FIASCO) (Cortinas et al., 2006) was used for microsatellite enrichment of $D$. siricidicola source Argentina1. This was followed by pyrosequencing as described by Santana et al. (2009).

\section{Primer design and amplification}

Sequences obtained from pyrosequencing were assembled into contigs using the ContigExpress component of Vector NTI Explorer software (Invitrogen, Carlsbad, CA, USA). From these contigs, microsatellite repeats were identified using the web-based program Simple Sequence Repeat Identification Tool (SSRIT) (Temnykh et al., 2001). The minimum number of repeats used in order to design primers for microsatellite containing sequences was five repeats for all repeat classes. Primers were designed using the PRIMER 3.0 software (Rozen and Skalestsky, 2000).

Primers were optimized and used on all $D$. siricidicola sources from harvested cultures (i.e. large numbers of nematodes pooled in each of the DNA isolation reactions). Polymerase Chain Reactions (PCR's) were performed using the thermal iCycler (Bio-Rad). DNA from various populations was used as the template in a $25 \mu$ reaction volume containing $10 \times$ PCR buffer $(10 \times$ solution, $100 \mathrm{mM}$ Tris- $\mathrm{HCl}, 500 \mathrm{mM} \mathrm{KCl}, \mathrm{pH}$ 8.3) (Roche Diagnostics GmbH, Germany), $25 \mathrm{mM} \mathrm{MgCl}_{2}$ (Roche Diagnostics GmbH), $10 \mathrm{mM}$ dNTPs, $10 \mu \mathrm{M}$ of each forward and reverse primer, FastStart Taq DNA Polymerase (Roche Diagnostics $\mathrm{GmbH}$ ) and sterile SABAX water was added to make up the total volume for PCR amplification. The thermocycler conditions were an initial denaturation step at $94{ }^{\circ} \mathrm{C}$ for $1 \mathrm{~min}$, followed by 30 cycles of denaturation at $94{ }^{\circ} \mathrm{C}$ for $30 \mathrm{~s}$, annealing at $55^{\circ} \mathrm{C}$ for $30 \mathrm{~s}$, extension at $72{ }^{\circ} \mathrm{C}$ for $1 \mathrm{~min}$ and a final extension step of $72{ }^{\circ} \mathrm{C}$ for $10 \mathrm{~min}$. PCR products were separated on $2 \%$ agarose gels, stained with ethidium bromide (EtBr) and visualized under UV transilluminator imaging system (UVP, United Kingdom). A 100 base-pair (bp) molecular weight marker (Fermentas, $\mathrm{O}^{\prime}$ Gene Ruler ${ }^{\mathrm{TM}}$ ) was used for size estimates of PCR products.

The presence of $A$. areolatum DNA in D. siricidicola extracted DNA was determined using basidiomycete primers, P-1 (5' TTG CAG ACG ACT TGA ATG G $3^{\prime}$ ) (Hsiau, 1996) and 5S-2B (5' CAC CGC ATC CCG TCT GAT CTG CG $3^{\prime}$ ) (Coetzee et al., 2000). These primers targeting the IGS rDNA region were also tested on $A$. areolatum isolate $\mathrm{F} 8 \mathrm{NCT}$ ( $A$. areolatum isolate from the field populations of $S$. noctilio in South Africa) using the same conditions as for D. siricidicola DNA.

For Southern Hemisphere sources of $D$. siricidicola, the microsatellite loci (excluding Ds 105, Ds 302, Ds 323, Ds 350 and Ds 366) were also amplified from four single nematodes from all sources. For single nematode amplification, nematodes were transferred from A. areolatum cultures using $0.80 \times 40 \mathrm{~mm}$ sterile needles (New Promex Corporation) into 96 well PCR microplates (Axygen Scientific, California) using a Stemmi 2000 microscope (Zeiss, Germany). Each well contained one nematode in a $25 \mu \mathrm{l}$ of the PCR reagent mixture as described above. The thermocycler conditions for amplification were an initial denaturation step at $95^{\circ} \mathrm{C}$ for $4 \mathrm{~min}$ followed by 35 cycles of denaturation at $94{ }^{\circ} \mathrm{C}$ for $30 \mathrm{~s}$, annealing at $60{ }^{\circ} \mathrm{C}$ for $30 \mathrm{~s}$, extension at $72{ }^{\circ} \mathrm{C}$ for $1 \mathrm{~min}$ and a final extension step of $72{ }^{\circ} \mathrm{C}$ for $10 \mathrm{~min}$. The PCR products were visualized as described above. In order to assess possible polymorphism, PCR products from single nematodes were separated by $15 \%$ polyacrylamide gel electrophoresis (PAGE) (30\% acrylamide, $10 \times$ Tris-borate-
EDTA buffer, 10\% APS and TEMED; $4 \mathrm{~h}$ at $160 \mathrm{~V}$ ). Once the run was complete, the gels were placed into a Syber Gold (Molecular Probes, Inc., Eugene, OR, USA) solution for $30 \mathrm{~min}$ and then visualized under the UV transilluminator.

\section{DNA sequencing}

PCR products were purified using 6\% Sephadex G-50 columns with $50-150 \mu \mathrm{m}$ bead size (SigmaAldrich, Germany) following manufacturer's instructions, before sequencing. Purified PCR products were used as template DNA in cycle sequence reactions using the ABI BigDye Terminator Cycle Sequencing Reaction Kit (Applied Biosystems). The same primers used for PCR amplification were used to sequence both strands during cycle sequencing reactions. The thermocycler conditions were 25 cycles of denaturation at $96{ }^{\circ} \mathrm{C}$ for $10 \mathrm{~s}$, annealing at $55^{\circ} \mathrm{C}$ for $15 \mathrm{~s}$ and extension at $60{ }^{\circ} \mathrm{C}$ for 4 min using the thermal $i$ Cycler (Bio-Rad). The products were purified as previously described and precipitated using the Concentrator 5301 (Eppendorf AG, Germany) at $45^{\circ} \mathrm{C}$ for $30 \mathrm{~min}$. Precipitated PCR products were run on an ABI PRISM 377 automated DNA sequencer (Applied Biosystems, California, USA).

\section{Results}

Both harvesting methods yielded large numbers of nematodes from which DNA was extracted. DNA extraction from the flaskreared nematodes using the phenol-chloroform method was considerably more labor intensive and time consuming compared to DNA extraction performed using PrepMan ${ }^{\mathrm{TM}}$ (Applied Biosystems, California, USA) from PDA cultures.

The outcomes of the FIASCO enrichment and pyrosequencing have previously been reported and compared with a similar application of these tools to the fungus Fusarium circinatum and S. noctilio by Santana et al. (2009). In summary, $1.2 \mathrm{Mb}$ of sequence data were generated using this method, which was assembled into 397 contigs or fragments represented by single reads. Of these, 166 fragments contained microsatellites with dinucleotides, trinucleotides and tetranucleotides, comprising $93 \%, 2 \%$ and $5 \%$ of the fragments, respectively.

A total of 26 primer pairs were designed to amplify microsatellite-containing loci, of which 17 could be optimized to amplify single fragments (Table 1). These fragments were confirmed to represent the loci of interest through sequencing and comparison with the original fragments. Amplifications were equally successful from DNA extracted from culture plates (including large numbers of nematodes per sample) and for amplifications from single nematodes. DNA of $A$. areolatum was detected in the extracted nematode DNA through amplification of the IGS rDNA region using the primers $\mathrm{P}-1$ and $5 \mathrm{~S}-2 \mathrm{~B}$. None of the primer pairs resulted in the amplification of fragments when DNA extracted from A. areolatum cultures was used in the reactions.

No length polymorphisms were identified in any of the 17 microsatellite containing loci using agarose and polyacrylamide gel electrophoresis for any of the five sources of $D$. siricidicola from the Southern Hemisphere. This was confirmed by sequencing 10 25 representative products for each of the 12 loci. These sequences also confirmed that there were no polymorphisms in regions flanking the microsatellites, except for one transition $(\mathrm{T} / \mathrm{C}$ ) observed for the strain Argentina2 for locus Ds316, compared to other sources of the nematode from the Southern Hemisphere. The sequence data for 17 primer pairs covered $3291 \mathrm{bp}$ including 327 bp of microsatellite repeated sequences.

Comparison of PCR product sequences for the 17 selected loci between Southern Hemisphere and Canadian sources of the nematode (DNA isolated from culture plates) revealed polymorphisms in 12 of the loci (Tables 1 and 2). These polymorphisms included 
microsatellite length variations, single nucleotide polymorphisms and insertions/deletions (indels) (Table 2).

\section{Discussion}

This study is the first to consider the diversity among populations of $D$. siricidicola from different regions in the Southern Hemisphere. It was expected that there might be reduced diversity and a genetic linkage between these populations, given their shared history of introduction and the expected bottlenecks resulting from the rearing process. The extent of homozygosity was, however, unexpected. Among 3291 bp of sequence data, spanning $327 \mathrm{bp}$ of microsatellite repeats, there was only one base pair variation between a source obtained from Argentina and all other sources of the nematode from the Southern Hemisphere. These results confirm that the Kamona strain has been distributed throughout the Southern Hemisphere, and from a single origin. In contrast, strains of $D$. siricidicola from Canada provided a firm basis for comparison and were clearly genetically distinct from all the Southern Hemisphere strains.

The analysis of the Southern Hemisphere populations of $D$. siricidicola using pooled DNA from cultures, confirmed by genotyping single nematodes from all populations, showed that a highly inbred population of the nematode exists throughout the Southern Hemisphere. This is likely the result of repeated genetic bottlenecks and inbreeding associated with the culturing and introduction of the nematode into new environments. When nematodes are reared, a circular plug of $13 \mathrm{~mm}$ in diameter containing between 100-2000 nematodes (Brett Hurley, unpublished data) is selected from a culture, which is then used to repeatedly produce subcultures. The plug is also likely to contain many nematode
Table 2

Summary of polymorphisms observed per locus.

\begin{tabular}{|c|c|c|c|c|c|}
\hline \multirow[t]{2}{*}{ Primers } & \multirow[t]{2}{*}{ Strains } & \multicolumn{3}{|c|}{ Types of polymorphism } & \multirow[t]{2}{*}{ No. of alleles } \\
\hline & & SSRs & SNPs & Insertion & \\
\hline \multirow[t]{2}{*}{ Ds 1} & $\mathrm{SH}$ & $(\mathrm{GTA})_{10}$ & $\mathrm{~A} / \mathrm{G}$ & - & 1 \\
\hline & Canadian & $(\mathrm{GTA})_{16}$ & & GTGGTAGT & 1 \\
\hline \multirow[t]{2}{*}{ Ds 54} & $\mathrm{SH}$ & No variation & - & CACATACA & 1 \\
\hline & Canadian & No variation & & - & 1 \\
\hline \multirow[t]{2}{*}{ Ds 83} & $\mathrm{SH}$ & No variation & $\mathrm{G} / \mathrm{T} ; \mathrm{A} / \mathrm{G}$ & - & 1 \\
\hline & Canadian & No variation & & - & 1 \\
\hline \multirow[t]{2}{*}{ Ds 105} & $\mathrm{SH}$ & $(\mathrm{AG})_{9}$ & $\mathrm{G} / \mathrm{A}$ & - & 1 \\
\hline & Canadian & $(A G)_{13}$ & & - & 1 \\
\hline \multirow[t]{2}{*}{ Ds 201} & $\mathrm{SH}$ & $(\mathrm{TG})_{7}$ & $\mathrm{G} / \mathrm{A}$ & $\mathrm{T}$ & 1 \\
\hline & Canadian & $(\mathrm{TG})_{4}$ & & - & 1 \\
\hline \multirow[t]{2}{*}{ Ds 302} & $\mathrm{SH}$ & No variation & - & - & 1 \\
\hline & Canadian & No variation & & $\mathrm{T}$ & 1 \\
\hline \multirow[t]{2}{*}{ Ds 316} & $\mathrm{SH}$ & $(\mathrm{GA})_{5}$ & - & - & 1 \\
\hline & Canadian & $(\mathrm{GA})_{7}$ & & - & 1 \\
\hline \multirow[t]{2}{*}{ Ds 323} & $\mathrm{SH}$ & $(\mathrm{TG})_{8}$ & $\mathrm{G} / \mathrm{T}$ & TTGT & 1 \\
\hline & Canadian & $(\mathrm{TG})_{7}$ & & - & 1 \\
\hline \multirow[t]{2}{*}{ Ds 325} & $\mathrm{SH}$ & $(\mathrm{GT})_{8}$ & $\mathrm{~A} / \mathrm{G} ; \mathrm{A} / \mathrm{T}$ & - & 1 \\
\hline & Canadian & $(\mathrm{GT})_{9}$ & & - & 2 \\
\hline \multirow[t]{2}{*}{ Ds 366} & $\mathrm{SH}$ & $(\mathrm{GT})_{5}$ & $\mathrm{~T} / \mathrm{A}$ & - & 1 \\
\hline & Canadian & $(\mathrm{GT})_{6}$ & & - & 1 \\
\hline \multirow[t]{2}{*}{ Ds 375} & $\mathrm{SH}$ & No variation & - & TGCACA & 1 \\
\hline & Canadian & No variation & & - & 1 \\
\hline \multirow[t]{2}{*}{ Ds 388} & $\mathrm{SH}$ & $(\mathrm{GT})_{4}(\mathrm{TG})_{10}$ & $\mathrm{C} / \mathrm{T}$ & - & 1 \\
\hline & Canadian & $(\mathrm{GT})_{5}(\mathrm{TG})_{7}$ & & - & 1 \\
\hline
\end{tabular}

SH-Southern Hemisphere sources (Argentina1, Argentina2, Australia, Brazil and South Africa) Canadian-Canadian sources (181, 184, 484, 1084).

siblings, since female nematodes lay their eggs in groups. Such sub-culturing typically occurs bi-weekly, until the nematodes are transferred onto flasks for mass production or stored in liquid nitrogen (Bedding and Iede, 2005). When D. siricidicola is intro-

Table 1

Primer sequences, expected locus size per SSR primers, no. of SR repeats and melting temperature per primer of Deladenus siricidicola.

\begin{tabular}{|c|c|c|c|c|c|c|}
\hline Locus & Primer name & Primer sequence $\left(5^{\prime} \rightarrow 3^{\prime}\right)$ & Expected size & Repeats & $T_{\mathrm{m}}\left({ }^{\circ} \mathrm{C}\right)$ & Polymorphism (SH vs Can) \\
\hline \multirow[t]{2}{*}{ Ds 1} & Ds. $1 \mathrm{~F}$ & CAATGTGCTGCGTCAATTTT & $157 \mathrm{bp}$ & $(\mathrm{GTA})_{10}$ & 56 & Yes \\
\hline & Ds. $1 \mathrm{R}$ & ACCCAACGCGTAGTGATAGC & & & 62 & \\
\hline \multirow[t]{2}{*}{ Ds 7} & Ds. 7F & TTCAATTTTGTGTCTGGCAAA & 249 bp & $(\mathrm{TG})_{6}$ & 55 & No \\
\hline & Ds. 7R & AGCCACAAATCGCGACATA & & & 58 & \\
\hline \multirow[t]{2}{*}{ Ds 19} & Ds. $19 \mathrm{~F}$ & CGTGACCGATTTCATTTTGC & 192 bp & $(\mathrm{TCC})_{5}$ & 58 & No \\
\hline & Ds. $19 \mathrm{R}$ & ACGACAGCGAAGAGAACGAT & & & 60 & \\
\hline \multirow[t]{2}{*}{ Ds 54} & Ds. 54F & CAGCCACAACAATTCACACC & 155 bp & $(\mathrm{CA})_{6}$ & 60 & Yes \\
\hline & Ds. $54 \mathrm{R}$ & GCACAAAAATCTCGCCTCAT & & & 58 & \\
\hline \multirow[t]{2}{*}{ Ds 83} & Ds. $83 \mathrm{~F}$ & AGGCATAGAGCGAGTGGAAA & 159 bp & $(\mathrm{GA})_{5}$ & 60 & Yes \\
\hline & Ds. $83 \mathrm{R}$ & TCTCACGAACTTGTCCCTCA & & & 59 & \\
\hline \multirow[t]{2}{*}{ Ds 105} & Ds. $105 \mathrm{~F}$ & TGGTAGCAATCGATCGAAAA & 150 bp & $(\mathrm{AG})_{9}$ & 56 & Yes \\
\hline & Ds. $105 \mathrm{R}$ & CGTGTCCACTTGTCCСТCTC & & & 56 & \\
\hline \multirow[t]{2}{*}{ Ds 201} & Ds. $201 \mathrm{~F}$ & TGCATAGCTGGCGATAAATG & 168 bp & $(\mathrm{TG})_{7}$ & 58 & Yes \\
\hline & Ds. $201 \mathrm{R}$ & CGAGTCACGTACGCATTAGC & & & 62 & \\
\hline \multirow[t]{2}{*}{ Ds 302} & Ds. $302 \mathrm{~F}$ & ATTGTTACGGTGTGGGCATT & 215 bp & $(\mathrm{AC})_{6}(\mathrm{CA})_{6}$ & 58 & Yes \\
\hline & Ds. $302 \mathrm{R}$ & TGGATGTCCGTCTGTTGTGT & & & 60 & \\
\hline \multirow[t]{2}{*}{ Ds 308} & Ds. $308 \mathrm{~F}$ & GCCTTTTCCTTAGCTGTTTGA & 155 bp & $(\mathrm{TG})_{6}$ & 59 & No \\
\hline & Ds. 308R & GTGGTCCTCСTCTCCCTTTT & & & 62 & \\
\hline \multirow[t]{2}{*}{ Ds 316} & Ds. $316 \mathrm{~F}$ & TGCGGATATCTTCTCATTGTAA & 382 bp & $(\mathrm{TC})_{7}(\mathrm{TC})_{5}$ & 57 & Yes \\
\hline & Ds. 316R & TCAAATGTTATGCGAAATTCTG & & & 55 & \\
\hline \multirow[t]{2}{*}{ Ds 318} & Ds. $318 \mathrm{~F}$ & AGGGTACTCATGCCGAGGTT & 127 bp & $(\mathrm{AC})_{6}$ & 63 & No \\
\hline & Ds. 318R & ATGCGTATGTGCAGTTGTGT & & & 58 & \\
\hline \multirow[t]{2}{*}{ Ds 323} & Ds. $323 \mathrm{~F}$ & TTTACCTGTTGGCTGTTACCG & 165 bp & $(\mathrm{TG})_{8}(\mathrm{TG})_{6}$ & 61 & Yes \\
\hline & Ds. 323R & TGGGGTAAAAGTGGATTGGA & & & 58 & \\
\hline \multirow[t]{2}{*}{ Ds 325} & Ds. $325 \mathrm{~F}$ & ACGCTTATGTGTGCCACTTG & 298 bp & $(\mathrm{TG})_{6}(\mathrm{GT})_{8}(\mathrm{TG})_{5}(\mathrm{CATA})_{5}$ & 60 & Yes \\
\hline & Ds. 325R & GGGTCTCTTGATGATGTTTCG & & & 61 & \\
\hline \multirow[t]{2}{*}{ Ds 350} & Ds. $350 \mathrm{~F}$ & AGTCCTGAGTAACCTCCACCA & 151 bp & $(\mathrm{GC})_{5}$ & 63 & No \\
\hline & Ds. $350 \mathrm{R}$ & TACGGTACGCTGATGCTCAC & & & 62 & \\
\hline \multirow[t]{2}{*}{ Ds 366} & Ds. $366 \mathrm{~F}$ & CGCTGCTGTACTGCTGTTTT & 152 bp & $(\mathrm{GT})_{5}$ & 60 & Yes \\
\hline & Ds. 366R & CACACAAATGCACACATGGA & & & 58 & \\
\hline \multirow[t]{2}{*}{ Ds 375} & Ds. $375 \mathrm{~F}$ & GGCAGCTGAAATGATGACAA & 188 bp & $(\mathrm{AC})_{5}$ & 58 & Yes \\
\hline & Ds. 375R & ATCATCATCAGCAATATCCTCA & & & 57 & \\
\hline \multirow[t]{2}{*}{ Ds 388} & Ds. $388 \mathrm{~F}$ & AAGTCAGCTGAAAGGCGAAG & $228 \mathrm{bp}$ & $(\mathrm{CA})_{10}(\mathrm{AC})_{4}$ & 60 & Yes \\
\hline & Ds. 388R & TGTGTGCATGAAAACGGAAC & & & 58 & \\
\hline
\end{tabular}


duced into new regions for biological control programs, only a few cultures are typically introduced. These steps of multiplication, bulking and transfer to new environments, repeated in many laboratories during the course of the last two decades, will inevitably have resulted in genetic bottlenecks and inbreeding for the Kamona strain of $D$. siricidicola. Results of this study confirm this view.

Founder effects and inbreeding have been shown to affect the population diversity of other nematodes in a similar fashion to $D$. siricidicola. For example, a study conducted on the pine wood nematode, Bursaphelenchus xylophilus, an introduced pathogen in Japan (Mamiya, 1987), showed a low degree of microsatellite polymorphism (relative genetic uniformity) in sub-populations (Zhou et al., 2007). This was attributed to a founder effect. Similarly, studies on the cyst nematodes Heterodera schachtti (Plantard and Porte, 2003; Plantard and Porte, 2004) and Globodera pallida (Picard et al., 2004) have shown that they are highly inbred species due to increased probability of interbreeding between siblings mating, which is influenced by their limited dispersal range. Larvae from a single cyst are siblings or half-siblings, depending on whether a single or several males fertilize a female. This mode of reproduction can significantly influence and reduce population diversity. The same situation appears to be true for $D$. siricidicola in the Southern Hemisphere.

Comparison of $D$. siricidicola sources from the Southern Hemisphere and Canada confirmed that each of these areas harbors a different strain of the nematode. Deladenus siricidicola was thought not to be present in North America, and was only recently discovered in that region (Bedding and Akhurst, 1978; Yu et al., 2009). Yu et al. (2009) confirmed the species identity using morphological characteristics and comparison with the Kamona strain based on DNA sequences. Using sequences for ribosomal DNA region and the cytochrome oxidase subunit 1 (COI), these authors also showed that there were sequence differences between North America $D$. siricidico$l a$ and the Kamona strain. These differences included seven substitutions and ten indels for the rDNA region, and two base pair differences for the COI. However, subsequent work has shown that a portion of the Canadian population is the same or similar to the Kamona strain (Isabel Leal, unpublished data). The microsatellite markers developed here will be useful to further characterize the differences between the Canadian and Kamona strain of $D$. siricidicola.

It is commonly accepted that $D$. siricidicola was accidentally introduced into Canada. Such an introduction would not be unusual, in view of the fact that the original discovery of the nematode in New Zealand during the early part of the 20th century resulted from its accidental introduction together with $S$. noctilio (Zondag, 1969). In tracing the origin of the $S$. noctilio invasion into the United States of America, Nielsen et al. (2009) showed that A. areolatum found in North America was represented by two genotypes, which were different from the genotypes found in the Southern Hemisphere (Slippers et al., 2001; Slippers et al., 2002). These results suggest that the invasions of $S$. noctilio into the Southern Hemisphere and North America represent two separate events. In contrast, a recent study using multiple locus sequence data has suggested that one of the genotypes of A. areolatum in Canada is identical to that in the Southern Hemisphere (Bergeron et al., 2011). This would imply a shared origin of introduction of S. noctilio into North America and the Southern Hemisphere. Regardless of whether there is a link between the $S$. noctilio introductions in North America and the Southern Hemisphere, the introduction of D. siricidicola appears not to be connected to that of the fungal strains observed in the Southern Hemisphere. This provides an opportunity for North American and Southern Hemisphere countries to exchange nematode strains and thus to increase genetic diversity and potentially the efficacy of biological control programs in these regions.
The loci for which markers have been developed in this study might have broader application than simply microsatellite length variation in populations of $D$. siricidicola. A number of loci also contained SNPs and indels in the microsatellite flanking regions. These variations were in some cases fixed in the populations, for example between those of the Kamona strain from the Southern Hemisphere and strains from Canada. These markers could thus be used for rapid distinction between the strains using sequencing, realtime PCR probes or primers, or PCR-RFLP screens (Nasmith et al., 1996; Aikawa et al., 2006).

Next generation sequencing coupled to microsatellite enrichment protocols has provided important new opportunities for the effective development of microsatellite markers for population studies, as illustrated in this study. The use of pyrosequencing enabled the exclusion of the time-consuming cloning step, generated substantially more microsatellite containing sequences than would have been feasible with the traditional cloning and Sanger sequencing approaches, and substantially reduced the overall costs associated with development of microsatellites. This tool has recently been described in a series of studies, with slight modifications, and applied widely to various organisms. These include the venomous copperhead snake Agkistrodon contortrix (Castoe et al., 2010), the pine pathogenic fungus $F$. circinatum, the pine-damaging woodwasp $S$. noctilio and its parasitic nematode $D$. siricidicola (Santana et al., 2009), ancient DNA of the extinct heavy-footed moa Pachyornis elephantopus (Allentoft et al., 2009), and New Zealand's endangered blue duck Hymenolaimus malacorhynchos (Abdelkrim et al., 2009). Interestingly, in the latter two studies, microsatellites are known to occur in low frequency, and yet this tool enabled characterization of markers that are crucial in understanding past biodiversity and extinction processes.

The nematode harvesting method used in this study did not rid the $D$. siricidicola samples of all residual $A$. areolatum fragments, even after multiple washes. This meant that DNA extracts contained a mixture of fungal and nematode DNA, and therefore a possibility of inadvertently developing primers from fungal sequences. All primers were therefore tested for their ability to amplify pure $A$. areolatum DNA, but this did not occur. This is probably because the fungal DNA was in a much lower concentration compared to the nematode DNA. The primers can thus now be applied in situations in which even greater amounts of fungal DNA are present.

It is of substantial concern that Southern Hemisphere populations of $D$. siricidicola appear to be highly inbred, and also homozygous, at most of the loci tested. This lack of diversity is likely to significantly reduce the ability of the nematode to adapt and establish itself in different environments, on different Pinus spp. and on different populations of $S$. noctilio (Roderick and Navajas, 2003; Hufbauer and Roderick, 2005). The environments in which the nematode is applied for biological control purposes include a variety of climate types, from Mediterranean winter-rainfall, to continental summer-rainfall, cold temperate winter rainfall and subtropical environments. In addition, various Pinus spp. are involved, including $P$. radiata, $P$. patula, P. elliottii, $P$. sylvestris, $P$. taeda, and $P$. caribaea, $P$. contorta var. latifolia and $P$. ponderosa. It is also known that the fungus $A$. areolatum, which is an obligate food source for the nematode, and different wasp populations can differ genetically and phenotypically across regions (Hurley et al., 2007, 2008). These authors also highlight the fact that there are other genera of fungi in trees where the nematode is applied, which also have the potential to reduce the efficacy of $D$. siricidicola as a biocontrol agent. These and probably other less obvious factors make it highly unlikely that a genetically homozygous population of $D$. siricidicola will be an effective biocontrol agent over the longer term. Thus, for an effective biological control program for the Southern Hemisphere, native and genetically diverse populations 
of $D$. siricidicola would need to be characterized and tested in different environments where biological control is required. Apart from native environments, New Zealand might also be a location from which diverse strains of $D$. siricidicola could be obtained, or observed. This region has had many introductions of the nematode spanning a long period of time. The Kamona strain of $D$. siricidicola has also not been deployed in New Zealand, and therefore the nematode populations in this country might be sufficiently genetically diverse to provide new sources of the biocontrol agent. The polymorphic markers produced in this study should be useful in future research requiring knowledge of the genetic diversity and structure of $D$. siricidicola populations.

\section{Acknowledgments}

We thank the University of Pretoria, the National Research Foundation, members of the Tree Protection Co-operative Program and THRIP funding from the Department of Trade and Industry, South Africa, for financial support. We also thank the Mandela Rhodes Foundation for financial support for the first author.

\section{References}

Abdelkrim, J., Robertson, B.C., Stanton, J.L., Gemmell, N.I., 2009. Fast, cost effective development of species-specific microsatellite markers by genomic sequencing. BioTechniques 46, 185-192.

Ahumada, R., 2002. Diseases in commercial Eucalytus plantations in Chile, with special reference to Mycosphaerella and Botryosphaeria species. MSc Thesis. University of Pretoria, Pretoria, RSA.

Aikawa, T., Kikuchi, T., Kosaka, H., 2006. Population structure of Bursaphelenchus xylophilus within Pinus thunbergii trees inoculated with two nematode isolates. Forest Pathology 36, 1-13.

Allentoft, M.E., Schuster, S.C., Holdaway, R.N., Hale, M.L., McLay, E., Oskam, C., Gilbert, M.T.P., Spencer, P., Willerslev, E., Bunce, M., 2009. Identification of microsatellites from an extinct moa species using high-throughput (454) sequence data. BioTechniques 46, 195-200.

Bedding, R.A., 1967. Parasitic and free-living cycles in entomogenous nematodes of the genus Deladenus. Nature 214, 174-175.

Bedding, R.A., 1972. Biology of Deladenus siricidicola (Neotylenchidae) an entomophagous- mycetophagous nematode parasitic in siricid woodwasps. Nematologica 18, 482-493.

Bedding, R.A., Akhurst, R.J., 1974. Use of the nematode Deladenus siricidicola in the biological control of Sirex noctilio in Australia. Journal of Australian entomology Society $13,129-135$.

Bedding, R.A., Akhurst, R.J., 1978. Geographic distribution and host preference of Deladenus species (Nematoda: Neotylenchidae) parasitic in siricid woowasps and associated hymenopterous parasitoids. Nematologica 24, 286-294.

Bedding, R.A., Iede, E.T., 2005. Application for Beddingia siricidicola for Sirex Woodwasp Control. In: Grewal, P., Ehlers, R., Shapiro-Ilan, D.I. (Eds.), Nematodes as Biocontrol Agents. CAB International, Wallingford, U.K, pp. 385-399.

Bergeron, M., Leal, I., Foord, B., Ross, G., Davis, C., Slippers, B., de Groot, P., Hamelin, R.C., 2011. Putative origin of clonal lineages of Amylostereum areolatum, the fungal symbiont associated with Sirex noctilio, retrieved from Pinus sylvestris, in eastern Canada. Fungal Biology 115, 750-758.

Castoe, T.A., Poole, A.W., Gu, W., DE Koning, A.P.J., Daza, J.M., Smith, E.N., Pollock, D.D., 2010. Rapid identification of thousands of copperhead snake (Agkistrodon contortrix) microsatellite loci from modest amounts of 454 shotgun genome sequence. Molecular Ecology Resources 10, 431-437.

Coetzee, M.P.A., Wingfield, B.D., Coutinho, T.A., Wingfield, M.J., 2000. Identification of the causal agent of Armillaria root rot of Pinus species in South Africa. Mycologia 92, 777-785.

Cortinas, M.N., Barnes, I., Wingfield, B.D., Wingfield, M.J., 2006. Polymorphic microsatellite markers for the Eucalyptus fungal pathogen Colletogloeopsis zuluensis. Molecular Ecology 6, 780-783.

de Groot, P., Nystrom, K., Scarr, T., 2006. Discovery of Sirex noctilio (Hymenoptera: Siricidae in Ontario, Canada. The Great Lakes Entomologist 39, 49-53.

Haugen, D.A., Underdown, M.G., 1990. Sirex noctilio control program in response to the 1987 Green Triangle outbreak. Australian Forestry 53, 33-40.

Hoebeke, E.R., Haugen, D.A., Haack, R.A., 2005. Sirex noctilio: Discovery of Palearctic siricid woodwasp in New York. Newsletter of the Michigan Entomological Society $50,24-25$.

Hsiau, O.T.W., 1996. The taxonomy and phylogeny of the mycangial fungi from Dendroctonus brevicomis and Dendroctonus frontalis (Coleoptera: Scolytidae) (PhD Thesis). Iowa State University, Ames,IA, USA.

Hufbauer, R.A., Roderick, G.K., 2005. Microevolution in biological control: Mechanisms, patterns and processes. Biological control 35, 227-239.
Hurley, B.P., Slippers, B., Wingfield, M.J., 2007. A comparison of control results for the alien invasive woodwasp. Sirex noctilio, in the southern hemisphere. Agricultural and Forest Entomology 9, 159-171.

Hurley, B.P., Slippers, B., Croft, P.K., Hatting, H.J., van der Linde, M., Morris, A.R., Dyer, C., Wingfield, M.J., 2008. Factors influencing parasitism of Sirex noctilio (Hymenoptera: Siricidae) by the nematode Dealdenus siricidicola (Nematoda: Neotylenchidae) in summer rainfall areas in South Africa. Biological Control 45, 450-459.

Iede, E.T., Penteado, S., Schaitza, E.G., 1998. Sirex noctilio problem in Brazil detection, evaluation and control. In: Iede, E., Shaitza, E., Penteado, S., Reardon, R., Murphy, T. (Eds.), Proceedings of a Conference. Training in the Control of Sirex noctilio by Use of Natural Enemies. USDA Forest Service, Morgantown, MV, pp. 45-52.

Klasmer, P., Fritz, G., Corley, J., Botto, E., 1998. Current status of research on Sirex noctilio F. in the Andean - Patagonian region in Argentina.. In: Iede, E., Shaitza, E., Penteado, S., Reardon, R., Murphy, T. (Eds.), Proceedings of a Conference. Training in the Control of Sirex noctilio by Use of Natural Enemies. USDA Forest Services, Morgantown, MV, pp. 89-90.

Maderni, J.F.P., 1998. Sirex noctilio present status in Uruguay, In: Iede, E., Shaitza, E., Penteado, S., Reardon, R., Murphy, T. (Eds.), Proceedings of a Conference. Training in the Control of Sirex noctilio by Use of Natural Enemies. USDA Forest Services, Morgantown, MV, pp. 81-82.

Mamiya, Y., 1987. Origin of the pine wood nematode and its distribution outside the United States. In: Wingfield, M.J. (Ed.), Pathogenicity of the Pine Wood Nematode. The American Phytopathological Society Press, St. Paul, Minnesota, USA, pp. 59-65.

Morgan, F.D., 1968. Bionomics of Siricidae Annual Review of Entomology 13, 239-256.

Nasmith, C.G., Speranzini, D., Jeng, R., Hubbes, M., 1996. RFLP Analysis of PCR Amplified ITS and 26S Ribosomal RNA Genes of Selected Entomopathogenic Nematodes (Steinernematidae, Heterorhabditidae). Journal of Nematology 28, 15-25.

Neumann, F.G., Morey, J.L., McKimm, R.J., 1987. The Sirex Woodwasp in Victoria. Bulletin no. 29, Department of Conservation, Forest and Lands, Australia, pp. 1-54.

Nielsen, C., Williams, D.W., Hajek, A.E., 2009. Putative source of the invasive Sirex noctilio fungal symbiont, Amylostereum areolatum, in the eastern United states and its association with native siricid woodwasps. Mycological Research 113, 1242-1253.

Picard, D., Plantard, O., Scurrah, M., Mugnièry, D., 2004. Inbreeding and population structure of the potato cyst nematode (Globodera pallida) in its native area (Peru). Molecular Ecology 13, 2899-2908.

Plantard, O., Porte, C., 2003. Isolation and characterization of microsatellite loci in the sugar beet cyst nematode Heterodera schachtii. Molecular Ecology Notes 3, 139-141.

Plantard, O., Porte, C., 2004. Population genetic structure of the sugar beet cyst nematode Heterodera schachtii: a gonochoristic and amphimictic species with highly inbred but weakly differentiated populations. Molecular Ecology 13, 33-41.

Roderick, G.K., Navajas, M., 2003. Genes in new environments: Genetics and evolution in biological control. Nature Reviews Genetics 4, 889-899.

Rozen, S., Skalestsky, H.J., 2000. PRIMER 3 on the WWW for general users and for biologist programmes. In: Krawets, S., Misener, S. (Eds.), Bionformatics Methods and Protocols: Methods in Molecular Biology. Humana Press, Totowa, New Jersey, pp. 365-386.

Santana, Q., Coetzee, M.P.A., Steenkamp, E., Mlonyeni, O.X.M., Hammond, G.N.A., Wingfield, B.D., Wingfield, M.J., 2009. Microsatellite discovery by deep sequencing of enriched genomic libraries. BioTechniques 46, 217-223.

Slippers, B., Wingfield, B.D., Coutinho, T.A., Wingfield, M.J., 2001. Population structure and possible origin of Amylostereum areolatum in South Africa. Plant Pathology 50, 206-210.

Slippers, B., Wingfield, B.D., Coutinho, T.A., Wingfield, M.J., 2002. DNA sequence and RFLP data reflect geographic spread and relationships of Amylostereum areolatum and its insect vectors. Molecular Ecology 11, 1845-1854.

Spradbery, J.P., Kirk, A.A., 1978. Aspects of the ecology of siricid woodwasp (Hymenoptera: Siricidae) in Europe, North Africa and Turkey with special reference to the biological control of Sirex noctilio F. in Australia. Bulletin of Entomological Research 68, 341-359.

Temnykh, S., Declerck, G., Lukashova, A., Lipovich, L., Cartinhour, S., McCouch, S., 2001. Computational and experimental analysis of microsatellites in rice (Oryza sativa L): frequeny, length variation, transposon association, and genetic marker potential. Genome Research 11, 1441-1452.

Tribe, G.D., 1995. The woodwasp Sirex noctilio Fabricius (Hymenoptera: Siricidae), a pest of Pinus species, now established in South Africa. African Entomology 3, 215-217.

Yu, Q., de Groot, P., Leal, I., Davis, C., Ye, W., Foord, B., 2009. Characterization of Deladenus siricidicola (Tylenchida: Neotylenchidae) associated with Sirex noctilio (Hymenoptera: Siricidae) in Canada. International Journal of Nematology 19, 23-32.

Zane, L., Bargelloni, L., Patarnello, T., 2002. Strategies for microsatellite isolation: a review. Molecular Ecology 11, 1-16.

Zhou, Z., Sakaue, D., Wu, B., Hogetsu, T., 2007. Genetic structure of populations of the pinewood nematode Bursaphelenchus xylophilus, the pathogen of pine wilt disease, between and within pine forests. Nematology 97, 304-310.

Zondag, R., 1969. A nematode infection of Sirex noctilio (F.) in New Zealand. Journal of Science 12, 732-747.

Zondag, R., 1979. Control of Sirex noctilio F. with Deladenus siricidicola Bedding. Part II. Introductions, establishments in the South Island 1968-75. New Zealand Journal of Science 9, 68-76. 